\title{
Description of Data Breaches Notifications in France and Lessons Learned for the Healthcare Stakeholders
}

\author{
Marie SIMON ${ }^{\mathrm{a}}$ and Vincent LOOTEN ${ }^{\mathrm{b}, 1}$ \\ ${ }^{a}$ Université Paris-Est Créteil, Créteil, France \\ ${ }^{\mathrm{b}}$ UMRS 1138, Centre de Recherche des Cordeliers, Université de Paris, Paris, France
}

\begin{abstract}
Although the consequences of the General Data Protection Regulation (GDPR) have been widely discussed, the violations have not been described in medical literature. In this study, we focus our analyses on the data breach notifications, in France, defined in the article 4 of GDPR as "a breach of security resulting, accidentally or unlawfully, in the destruction, loss, alteration, unauthorized disclosure of personal data transmitted, stored or otherwise processed, or unauthorized access to such data." Among 3,824 data breach notifications reported between May 2018 and February 2020, 244 (6.4\%) is related to the health sector. Loss of confidentiality is the most important breach $(80.7 \%)$ in this sector, followed by the loss of availability (27.5\%). Malicious cause occurred in $58.2 \%$ of them. We hypothesized a phenomenon of underreported data breach incidents in health due to a mismatch between cybersecurity and data privacy issues.
\end{abstract}

Keywords. Policy, Data Privacy, Cybersecurity

\section{Introduction}

In 2017, the WannaCry cyberthreat affected more than 600 organizations as the National Health Service (NHS) in England; in 2018 the Singapore Health System reported a major breach of over one million of patient records: cybersecurity attacks are a growing threat to healthcare. Included in the General Data Protection Regulation (GDPR), cybersecurity in health is a major issue for the next decade. Although the consequences of GDPR have been widely discussed, the violations have not been described in medical literature. Since May 2018, the GDPR provides the mandatory legal framework for all data processing including European citizens' personal data[1]. National authorities across the European Union can sanction any company or administration performing non-conform data processing regarding to the GDPR. From the researcher's perspective, Peloquin et al.[2] exposed some technical challenges for data reuse: the anonymization or the pseudonymization of personal data, the management of consent, the cross-border transfers of personal data and the right limitations in the research context. Furthermore, Bernd Blobel and Pekka Ruotsalainen[3] proposed a model to implement data governance and data access management into a medical information systems. However, a description of the GDPR violations recorded by the national authorities in Europe could

\footnotetext{
${ }^{1}$ Corresponding Author, Dr Vincent Looten, Université de Paris, Paris, France; E-mail: lootenv@gmail.com
} 
provide essential information about the legal practice of this regulation and the impact on its implementation. In this study, we focus our analyses on the data breach notifications defined in the article 4 of GDPR as "a breach of security resulting, accidentally or unlawfully, in the destruction, loss, alteration, unauthorized disclosure of personal data transmitted, stored or otherwise processed, or unauthorized access to such data". The aim is to describe data breach notifications in France.

\section{Methods}

Definitions. The French national authority for data privacy is the CNIL ("Commission nationale de l'informatique et des libertés" in French). The GDPR have made mandatory to notify the CNIL of any personal data breach that poses a risk to the rights and freedoms of personal data. This notification to the CNIL must be made within 72 hours, by the responsible for processing or by its representative.

Data sources. We extracted data breach notifications reported to the CNIL from May 2018 to February 2020. The code and the data used in this study are available at www.github.com/vlooten/databreach, while more recent data can be downloaded from the open data governmental website (www.data.gouv.fr).

Outcomes. Three types of violation were described: the loss of confidentiality, the loss of integrity and the loss of availability. These categories are not exclusive. We described the number of people impacted by the breaches according to the same categories proposed in the original dataset. We described the cause of the breach (accidental, malicious or unknown) and the origin (Internal, external or unknown). Data breaches included individual identifiers are at higher risk regarding GDPR regulation. Thereby, we performed a focus in the health notification to compare data breaches included or not the national identification number ("numéro d'inscription au répertoire national des personnes physiques" or NIR in French), which is a permanent identifier throughout the individual's lifetime.

Statistical analyses. Data were expressed as numbers (\%). Chi2 tests (for categorical data) was used to compare groups. All tests involved use of R 3.6.1(R Foundation, Vienna, Austria).

\section{Results}

Among 3,824 data breach notifications reported between May 2018 and February 2020, $675(17.7 \%)$ are related to the administration, $660(17.3 \%)$ to science and education activities, $485(12.7 \%)$ to the financial and insurance activities, $326(8.5 \%)$ to the Information and communication sectors and $244(6.4 \%)$ to the Health sector. Table 1 presents a description of the whole dataset and a comparison between Health sector and the other activities.

Among the 503 notifications included the national identification number (NIR), 121 $(24.1 \%)$ are related to the administration, $112(22.3 \%)$ to the science and education, 87 $(17.3 \%)$ to the commercial and industrial sectors, $71(14.1 \%)$ to the financial and insurance activities, $36(7.2 \%)$ to the health sector $28(5.6 \%)$ to the information and communication sectors, and $48(9.5 \%)$ to other sectors. Table 2 proposed a description of the data breach notification for the health sector and a comparison between notification included NIR and the others. 
Table 1. Description of the data breach notification and comparison between Health sector and the other sectors

\begin{tabular}{|c|c|c|c|c|}
\hline & $\begin{array}{c}\text { All } \\
\text { notifications } \\
(\mathrm{N}=\mathbf{3 8 2 4}) \\
\end{array}$ & $\begin{array}{l}\text { Health sector } \\
(\mathrm{N}=\mathbf{2 4 4})\end{array}$ & $\begin{array}{l}\text { Other activity } \\
\quad(\mathrm{N}=\mathbf{3 5 8 0})\end{array}$ & p value \\
\hline $\begin{array}{l}\text { Year of } \\
\text { accident } \\
2018 \\
2019 \\
2020\end{array}$ & $\begin{array}{l}1170(30.6 \%) \\
2287(59.8 \%) \\
367(9.6 \%)\end{array}$ & $\begin{array}{l}41(16.8 \%) \\
174(71.3 \%) \\
29(11.9 \%)\end{array}$ & $\begin{array}{l}1129(31.5 \%) \\
2113(59.0 \%) \\
338(9.44 \%)\end{array}$ & $<0.001$ \\
\hline $\begin{array}{l}\text { Type of } \\
\text { violation } \\
\text { Loss of } \\
\text { confidentiality }\end{array}$ & $3450(90.2 \%)$ & $197(80.7 \%)$ & $3253(90.9 \%)$ & $<0.001$ \\
\hline Loss of integrity & $406(10.6 \%)$ & $27(11.1 \%)$ & $379(10.6 \%)$ & 0.898 \\
\hline $\begin{array}{l}\text { Loss of } \\
\text { availability }\end{array}$ & $659(17.2 \%)$ & $67(27.5 \%)$ & $592(16.5 \%)$ & $<0.001$ \\
\hline $\begin{array}{l}\begin{array}{l}\text { Number of } \\
\text { people } \\
\text { impacted }\end{array} \\
<=5 \\
{[6-50]} \\
{[51-300]} \\
{[301-5000]} \\
>=5000\end{array}$ & $\begin{array}{l}919(24.0 \%) \\
652(17.1 \%) \\
746(19.5 \%) \\
1010(26.4 \%) \\
497(13.0 \%)\end{array}$ & $\begin{array}{l}69(28.3 \%) \\
50(20.5 \%) \\
56(23.0 \%) \\
45(18.4 \%) \\
24(9.84 \%)\end{array}$ & $\begin{array}{l}850(23.7 \%) \\
602(16.8 \%) \\
690(19.3 \%) \\
965(27.0 \%) \\
473(13.2 \%)\end{array}$ & 0.009 \\
\hline $\begin{array}{l}\text { Cause of } \\
\text { accident } \\
\text { Accidental } \\
\text { Malicious } \\
\text { Unknown }\end{array}$ & $\begin{array}{l}1151(30.1 \%) \\
2138(55.9 \%) \\
535(14.0 \%)\end{array}$ & $\begin{array}{l}62(25.4 \%) \\
142(58.2 \%) \\
40(16.4 \%)\end{array}$ & $\begin{array}{l}1089(30.4 \%) \\
1996(55.8 \%) \\
495(13.8 \%)\end{array}$ & 0.516 \\
\hline $\begin{array}{l}\text { Origin of } \\
\text { accident } \\
\text { Internal } \\
\text { External } \\
\text { Unknown } \\
\end{array}$ & $\begin{array}{l}1060(27.7 \%) \\
2229(58.3 \%) \\
535(14.0 \%) \\
\end{array}$ & $\begin{array}{l}64(26.2 \%) \\
140(57.4 \%) \\
40(16.4 \%) \\
\end{array}$ & $\begin{array}{l}996(27.8 \%) \\
2089(58.4 \%) \\
495(13.8 \%) \\
\end{array}$ & 0.200 \\
\hline
\end{tabular}

Table 2. Comparison between data breach notifications with NIR and without NIR in the health sector

\begin{tabular}{|c|c|c|c|c|}
\hline & $\begin{array}{c}\text { Health sector } \\
(\mathrm{N}=\mathbf{2 4 4})\end{array}$ & $\begin{array}{c}\text { Included NIR } \\
(\mathrm{N}=\mathbf{3 6})\end{array}$ & $\begin{array}{c}\text { Without NIR } \\
(\mathrm{N}=208)\end{array}$ & p value \\
\hline \multicolumn{5}{|l|}{$\begin{array}{l}\text { Year of } \\
\text { accident }\end{array}$} \\
\hline 2018 & $41(16.8 \%)$ & $5(13.9 \%)$ & $36(17.3 \%)$ & 0.809 \\
\hline 2019 & $174(71.3 \%)$ & $26(72.2 \%)$ & $148(71.2 \%)$ & \\
\hline 2020 & $29(11.9 \%)$ & $5(13.9 \%)$ & $24(11.5 \%)$ & \\
\hline \multicolumn{5}{|l|}{$\begin{array}{l}\text { Type of } \\
\text { violation }\end{array}$} \\
\hline $\begin{array}{l}\text { Loss of } \\
\text { confidentiality }\end{array}$ & $197(80.7 \%)$ & $29(80.6 \%)$ & $168(80.8 \%)$ & 1.000 \\
\hline Loss of integrity & $27(11.1 \%)$ & $7(19.4 \%)$ & $20(9.62 \%)$ & 0.090 \\
\hline $\begin{array}{l}\text { Loss of } \\
\text { availability }\end{array}$ & $67(27.5 \%)$ & $13(36.1 \%)$ & $54(26.0 \%)$ & 0.290 \\
\hline \multicolumn{5}{|l|}{$\begin{array}{l}\text { Number of } \\
\text { people } \\
\text { impacted }\end{array}$} \\
\hline$<=5$ & $69(28.3 \%)$ & $4(11.1 \%)$ & $65(31.2 \%)$ & 0.003 \\
\hline$[6-50]$ & $50(20.5 \%)$ & $3(8.33 \%)$ & $47(22.6 \%)$ & \\
\hline$[51-300]$ & $56(23.0 \%)$ & $14(38.9 \%)$ & $42(20.2 \%)$ & \\
\hline [301-5000] & $45(18.4 \%)$ & $10(27.8 \%)$ & $35(16.8 \%)$ & \\
\hline$>=5000$ & $24(9.84 \%)$ & $5(13.9 \%)$ & $19(9.13 \%)$ & \\
\hline
\end{tabular}




\begin{tabular}{ll|lll}
$\begin{array}{l}\text { Cause of } \\
\text { accident }\end{array}$ & & & & \\
Accidental & $62(25.4 \%)$ & $10(27.8 \%)$ & $52(25.0 \%)$ & 0.162 \\
Malicious & $142(58.2 \%)$ & $24(66.7 \%)$ & $118(56.7 \%)$ & \\
Unknown & $40(16.4 \%)$ & $2(5.56 \%)$ & $38(18.3 \%)$ & \\
\hline $\begin{array}{l}\text { Origin of } \\
\text { accident }\end{array}$ & & & & \\
Internal & $64(26.2 \%)$ & $9(25.0 \%)$ & $55(26.4 \%)$ & 0.127 \\
External & $140(57.4 \%)$ & $25(69.4 \%)$ & $115(55.3 \%)$ & \\
Unknown & $40(16.4 \%)$ & $2(5.56 \%)$ & $38(18.3 \%)$ & \\
\hline
\end{tabular}

\section{Discussion}

Main results. Among 3,824 data breach notifications reported between May 2018 and February $2020,244(6.4 \%)$ is related to the health sector, increasing by a factor four between 2018 and 2019. Data breach characteristics of the health sector were similar to data breach characteristics of the other sectors. Loss of confidentiality is the most important breach $(80.7 \%)$ in health sector, followed by the loss of availability $(27.5 \%)$, some data breaches are mixed. 175 (71.7\%) notifications reported fewer than 300 people impacted. Malicious cause occurred in $58.2 \%$ of them, accidental cause accounted for $25 \%$.

Technical significance. Firstly, we didn't find important differences between data breach notifications in health and the other sectors but may lead to higher threat for citizens regarding to international experience [4]. Secondly, the French ministry of health and the French digital health agency have reported 327 incidents in 2018 and 392 in 2019 , included respectively 276 and 333 hospitals. The rates of malicious incidents were $41 \%$ in 2018 and $43 \%$ in 2019[5]. Authorities hypothesized a phenomenon of underreported incidents: "The total number of reports is still low compared to the number of structures concerned by the reporting obligation (more than 3,000) and the probability that at least half of the structures concerned have had to deal with an incident that has impacted its normal operation during the year." Our results are similar with a lower amount of data breaches notification. Worldwide, healthcare lead in number of incidents $(27 \%)$, as described in 2018 by the European Union Agency for Network and Information Security report [6], which is much more than the 6,4\% notified in France based on our results. Thirdly, regarding the increase of data reuse for research purposes in France [7], the data processing included national identification numbers are regulated by the French law [8]. Nevertheless, only $36(14.8 \%)$ notifications in the health sector included NIR, with $4(11.1 \%)$ data breaches impacted 5 people or lower, which is nonrealistic. Therefore, we hypothesized a phenomenon of underreported data breach incidents due to a mismatch between cybersecurity and data privacy issues. This underreported is likely a violation of GDPR. We could explain this underreporting by the distinction between data privacy and cybersecurity in the hospitals' organization in France. Data privacy is managed by the chief information officers with the data protection officer as advisors; they are focus on users' community and data processing purposes. Cybersecurity is leads by the chief information security officers focus on the data infrastructure integrity. We hypothesized that all data breaches cannot be detected by the chief information security officers (e.g. breaches with 5 people or less or internal breaches).

Perspectives and recommendations. Dean F. Sittig and Hardeep Singh[9] proposed a four steps socio-technical approach that organizations can undertake to secure an 
electronic health record system: (1) To ensure adequate system protection by correctly installing and configuring computers and networks (2) To ensure more reliable system defense by implementing user focused strategies (3) To ensure a comprehensive system monitoring of suspicious activities, and (4) To respond, to recover, to investigate, and to learn from ransomware attacks. For practical implementation, we recommend: (1) to plan seasonal assessments of information security management systems and to try to meet the international standards for information security with long-term and comprehensive perspectives as recommended by W.-S. Park at al[10], (2) to reduce the end point complexity (due to a technology saturated environment) and improving internal stakeholder alignment as recommended by M.S. Jalali, and J.P. Kaiser[11]. Finally, to improve the completeness of data breaches notification database, an electronic declaration system could be proposed to all users of the information system included physicians and patients.

Conclusion. We highlight a phenomenon of underreported data breach incidents in health possibly due to a mismatch between cybersecurity and data privacy issues.

\section{References}

[1] Demotes-Mainard J, Cornu C, Guérin A, et al. How the new European data protection regulation affects clinical research and recommendations? Therapies. 2019; 74: 31-42. doi:10.1016/j.therap.2018.12.004.

[2] Peloquin D, DiMaio M, Bierer B, and Barnes M. Disruptive and avoidable: GDPR challenges to secondary research uses of data. Eur. J. Hum. Genet. 2020. doi:10.1038/s41431-020-0596-X.

[3] Blobel B and Ruotsalainen P. How Does GDPR Support Healthcare Transformation to 5P Medicine?, Stud. Health Technol. Inform. 2019; 264: 1135-1139. doi:10.3233/SHTI190403.

[4] Ghafur S, Kristensen S, Honeyford K, Martin G, Darzi A, and Aylin P. A retrospective impact analysis of the WannaCry cyberattack on the NHS. Npj Digit. Med. 2019; 2: 98. doi:10.1038/s41746-019-01616.

[5] Observatoire des signalements d'incidents de sécurité des systèmes d'information pour le secteur santé. 2019. Ministère des solidarités et de la santé et Agence du Numérique en Santé. esante.gouv.fr/sites/default/files/media_entity/documents/ans_acss_rapport_public_observatoire_signal ements_issis_2019_v0.10.pdf.

[6] ENISA Threat Landscape Report 201815 Top Cyberthreats and Trends. European Union Agency for Network and Information Security. doi:10.2824/622757

[7] Looten V and Simon M. Impact Analysis of the Policy for Access of Administrative Data in France: A Before-After Study. Stud. Health Technol. Inform. 2020; 270: 1133-1137. doi:10.3233/SHTI200339.

[8] Tout savoir sur le décret « cadre NIR » dans le champ de la protection sociale. Commission Nationale de l'Informatique et des Libertés, (2020). https://www.cnil.fr/fr/tout-savoir-sur-le-decret-cadre-nir-dans-lechamp-de-la-protection-sociale.

[9] Sittig D and Singh H. A Socio-technical Approach to Preventing, Mitigating, and Recovering from Ransomware Attacks. Appl. Clin. Inform. 2016; 7: 624-632. doi:10.4338/ACI-2016-04-SOA-0064.

[10] Park W-S, Seo S-W, Son S-S, Lee M-J, Kim S-H, Choi E-M, Bang J-E, Kim Y-E, and Kim O-N. Analysis of Information Security Management Systems at 5 Domestic Hospitals with More than 500 Beds. Healthc. Inform. Res. 2010; 16: 89. doi:10.4258/hir.2010.16.2.89.

[11] Jalali MS and Kaiser JP. Cybersecurity in Hospitals: A Systematic, Organizational Perspective. J. Med. Internet Res. 2018; 20: e10059. doi:10.2196/10059. 